\title{
Numerical Analysis of the Cross-Wedge of a Hollow Rail Axle
}

\author{
Zbigniew Pater ${ }^{1 *}$, Konrad Lis ${ }^{1}$, Patrycja Walczuk-Gągała ${ }^{1}$ \\ 1 Department of Mechanical Engineering, Lublin University of Technology, Nadbystrzycka 36, 20-718 Lublin, \\ Poland \\ * Corresponding author's e-mail: z.pater@pollub.pl
}

\begin{abstract}
The article presents an innovative method of manufacturing hollow rail axles using three combined wedge rolls. The proposed solution was evaluated using numerical simulation. Two cases of forming, differing in the wall thickness of the billet, were analysed. The geometry of the formed axles, distributions of the effective strain, temperature and damage function were presented. Moreover, the changes to the forces and torques acting on each roll were presented.
\end{abstract}

Keywords: cross wedge rolling, rail axle, FEM

\section{INTRODUCTION}

Rail axles are large-size products manufactured in large series. Currently these elements are manufactured using open die forging in hydraulic presses (with the pressure $8-15 \mathrm{MN}$ ) or a four-hammer radial forging machine (pressure 6.5 MN each) [3]. In order to increase the effectiveness and decrease the energy consumption of the forming process new methods of manufacturing, based on cross-wedge rolling (CWR) are researched. The main problem in the CWR process is the size of the machines and tools.

In the classic solution, the diameter of rolls may reach $3 \mathrm{~m}$, which is an impossible/unreal value. For this reason, the possibility of manufacturing rail axles using the multi-wedge rolling method, where the workpiece is simultaneously formed by 2 or 3 pairs of wedges [12]. Such a solution allows one to significantly decrease the diameter of rolls to c.a. $1600 \mathrm{~mm}[8,9]$, which is an implementable size. The experimental tests (1:5 scale models) indicated that the accuracy of the product manufactured using the multiwedge rolling method is unsatisfactory $[8,13]$. An effective elimination of the ovalization of the cross-section, typical for the two-roll method $[1,10,11]$, poses a significant problem.
Another concept of manufacturing rail axles has been developed in Lublin University of Technology [4]. The rolling process is divided into two stages. Firstly, the central step is formed and later on, the end steps (second pair of rolls). Inn this solution, it is possible to decrease the diameter of tools to $1200 \mathrm{~mm}$ and eliminate the possibility of inner cracks occurring. The downside to this method is the necessity to move the workpiece from one pair of rolls to the other, which may negatively influence the accuracy of forming.

Due to the development of high-speed rail a demand for hollow rail axles increases. It is estimated that only in China, until 2021, the demand for the hollow axles will reach 1 million [12]. It is therefore reasonable to seek new solutions allowing quick and waste-free manufacturing of hollow axles. It is known that in the case of CWR the three-roll method proves the most beneficial $[2,5,6]$. For this reason the concepts of an innovative method of manufacturing hollow rail axles using three combined rolls have been developed in Lublin University of Technology. The verification of the proposed solution was done using numerical simulation, the results of which are presented in this study. 


\section{The concept of rolling and the applied numerical model}

The analysis comprised of the forming process of a hollow rail axle, the shape and outer dimensions of which are shown in Figure 1. The inner dimensions depended on the inner diameter of the billet, mainly a thick-walled tube. It was assumed that the outer diameter of the tube is equal $202 \mathrm{~m}$, the inner diameter - either $122 \mathrm{~mm}$ or $82 \mathrm{~mm}$. The length of the billet was respectively $930 \mathrm{~mm}$ or $860 \mathrm{~mm}$ for the tube with thinner and thicker wall.

It was assumed that the rolling process will be conducted using three tools (combined rolls) located around the circumference of the workpiece, one by each $120^{\circ}$. One of the tools is presented in Figure 2. The axes of the rolls are placed parallel to the axis of the billet and $500 \mathrm{~mm}$ from it. With such parameters the minimum gap between each pair of rolls is equal $7 \mathrm{~mm}$. Each combined roll consists of one central roll and two side rolls. The central roll is rigidly mounted on the shaft, whereas the side rolls are supported on the shaft, along which they are able to move also axially. Wedges, shaping each step of the rail axle are located on the rolls (on the perimeter $315^{\circ}$ ).

The axles are shaped during two rotations of the tools. During the first rotation, the wedges located on the central rolls form the central step of the $1200 \mathrm{~mm}$-long axle. After the movement of the central rolls is ceased, the side rolls are moved

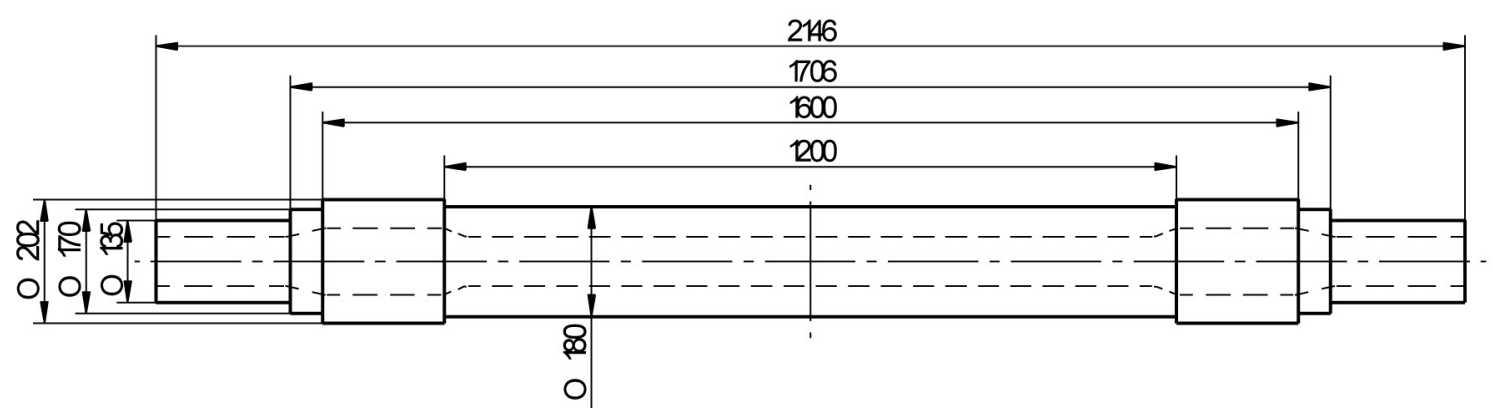

Fig. 1. The analysed hollow rail axle
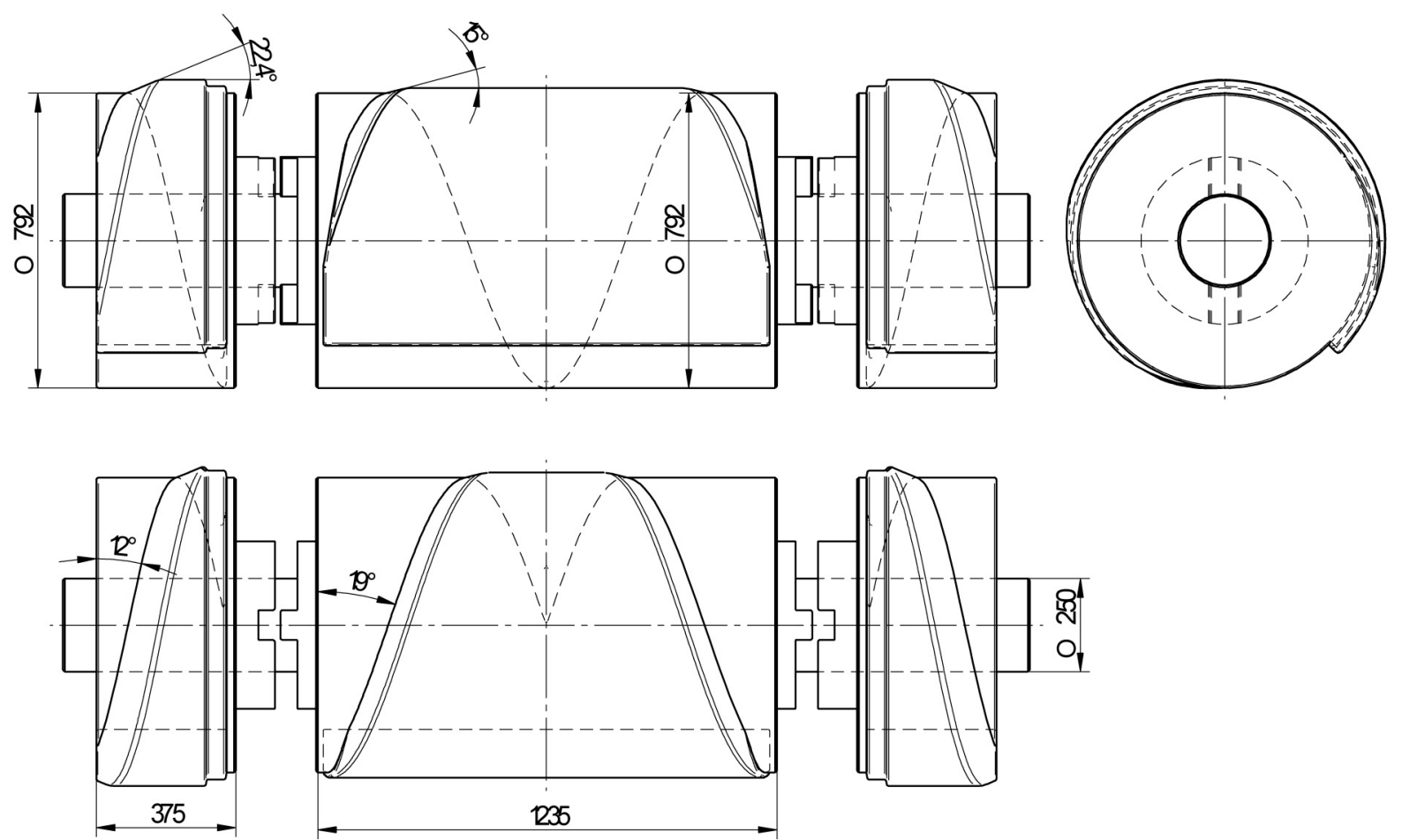

Fig. 2. Combined roll designed for forming the hollow rail axle in a system comprising of three wedge rolls 
towards the central rolls and, as a result, combined with the central roll. After restarting the forging machine, during the second rotation of the rolls the end steps of the axle are formed.

In order to assess the correctness of the proposed solution, a model of the process, shown in Figure 3, was developed in Simufact.Forming software. To simplify the calculations the symmetry of the process was applied and forming of one half of the axle was analysed. It was assumed that all of the tools behaved like perfectly rigid bodies, whereas the workpiece - elasto-plastic body. The material model of the axle, that is $42 \mathrm{Cr} 4$ grade steel, was taken from the library of the used software. It was assumed that the entire billet (thick-walled tube) was heated to $1200{ }^{\circ} \mathrm{C}$ before rolling. The temperature of the tools was constant and equal $250^{\circ} \mathrm{C}$, while the heat transfer coefficient was $10000 \mathrm{~W} / \mathrm{m}^{2} \mathrm{~K}$. It was moreover assumed that the rolls move at 8 rotations/minute, whereas the infeed ratio for the side rolls is equal $50 \mathrm{~mm} / \mathrm{s}$. Friction was modelled using the Tresca model, for which the friction factor was assumed to be equal 0.8 .

The workpiece was modelled using hexahedral elements assuming that the basic size of the element is equal $10 \mathrm{~mm}$. In the areas of the change of diameters the mesh density was increased and the size of the element was decreased to $5 \mathrm{~mm}$. During the calculations remeshing was used. It occurred when the growth of effective strain exceeded 0.4 . An exemplary division of the billet and the rolled axle into elements is shown in Figure 4.

\section{RESULTS}

The numerical analysis confirmed the validity of the presented concept of forming hollow rail axles. Figure 5 shows the progress of axle forming from the billet with smaller wall thickness, mainly $g_{0}=40 \mathrm{~mm}$. The results of the calculations indicate that the rolling process is stable and limits in the form of an uncontrolled slip do not occur at any stage of the process.

The following Figures 6 and 7 present the longitudinal and cross sections of rail axles formed from the billet with wall thickness 40 and $60 \mathrm{~mm}$. An analysis of those sections shows that in all of the formed steps the expected circular shape was obtained. Therefore it can be stated that in the proposed method the problem with effective removal of the ovalisation of the cross-section, a major limit to the rolling process, does not occur.

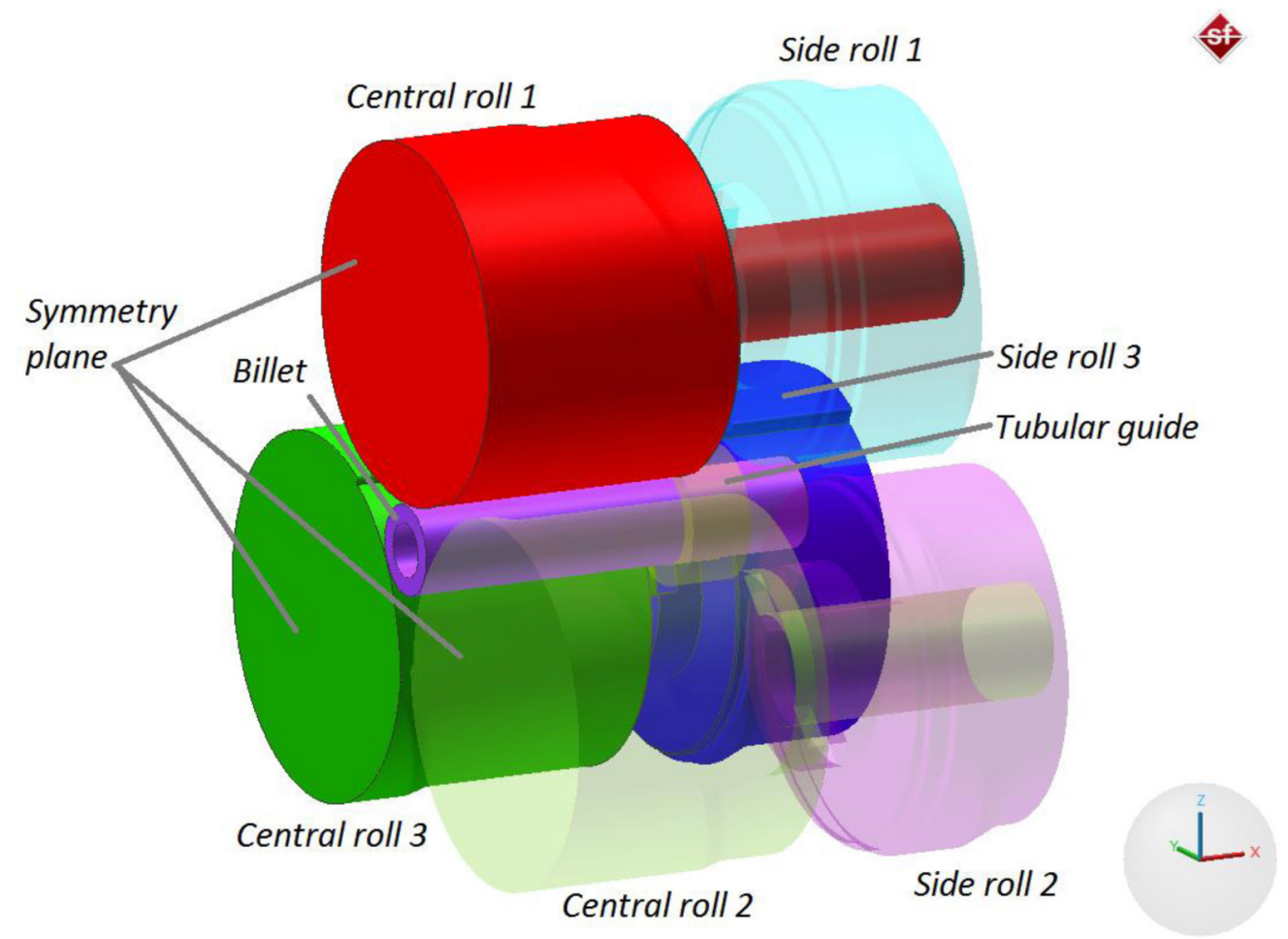

Fig. 3. Geometrical model of the analysed process of rolling a hollow rail axle (from a billet with $40 \mathrm{~mm}$-thick wall), created in Simufact Forming and considering the forming symmetry 


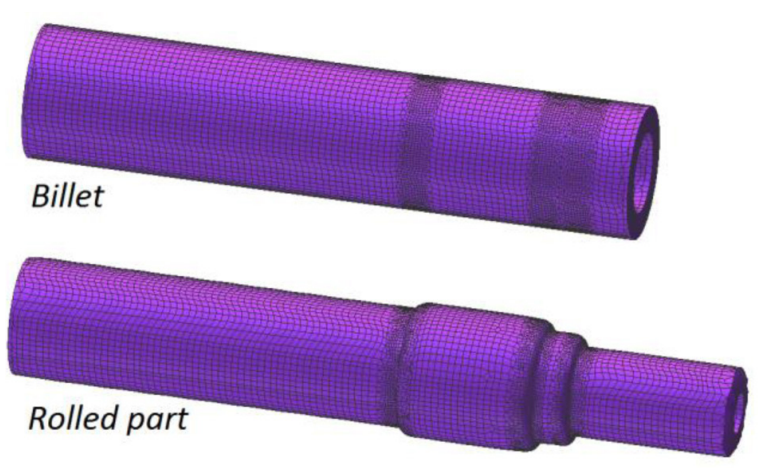

Fig. 4. The method of dividing the formed axle into elements; the example of rolling from a billet with $40 \mathrm{~mm}$-thick wall
As far as wall thickness is concerned it was stated that in the case of the axle rolled from the billet with $\mathrm{g}_{0}=40 \mathrm{~mm}$ wall thickness of the central step nearly did not change, whereas in the case of end steps an insignificant thickening of the wall, to c.a. $42 \mathrm{~mm}$, occurred. In the areas of changes to the outer perimeter thickening of the wall, up to $34 \mathrm{~mm}$, was observed. In the case of the axle rolled from the billet with $g_{0}=60 \mathrm{~m}$ the thickness of the central step decreased insignificantly (to $59.5 \mathrm{~mm}$ ), whereas for the end step thinning of the wall was significant (to $g=50 \mathrm{~mm}$ ). The smallest thickness of the wall, occurring in the areas of outer diameter change was $42.5 \mathrm{~mm}$. Generally
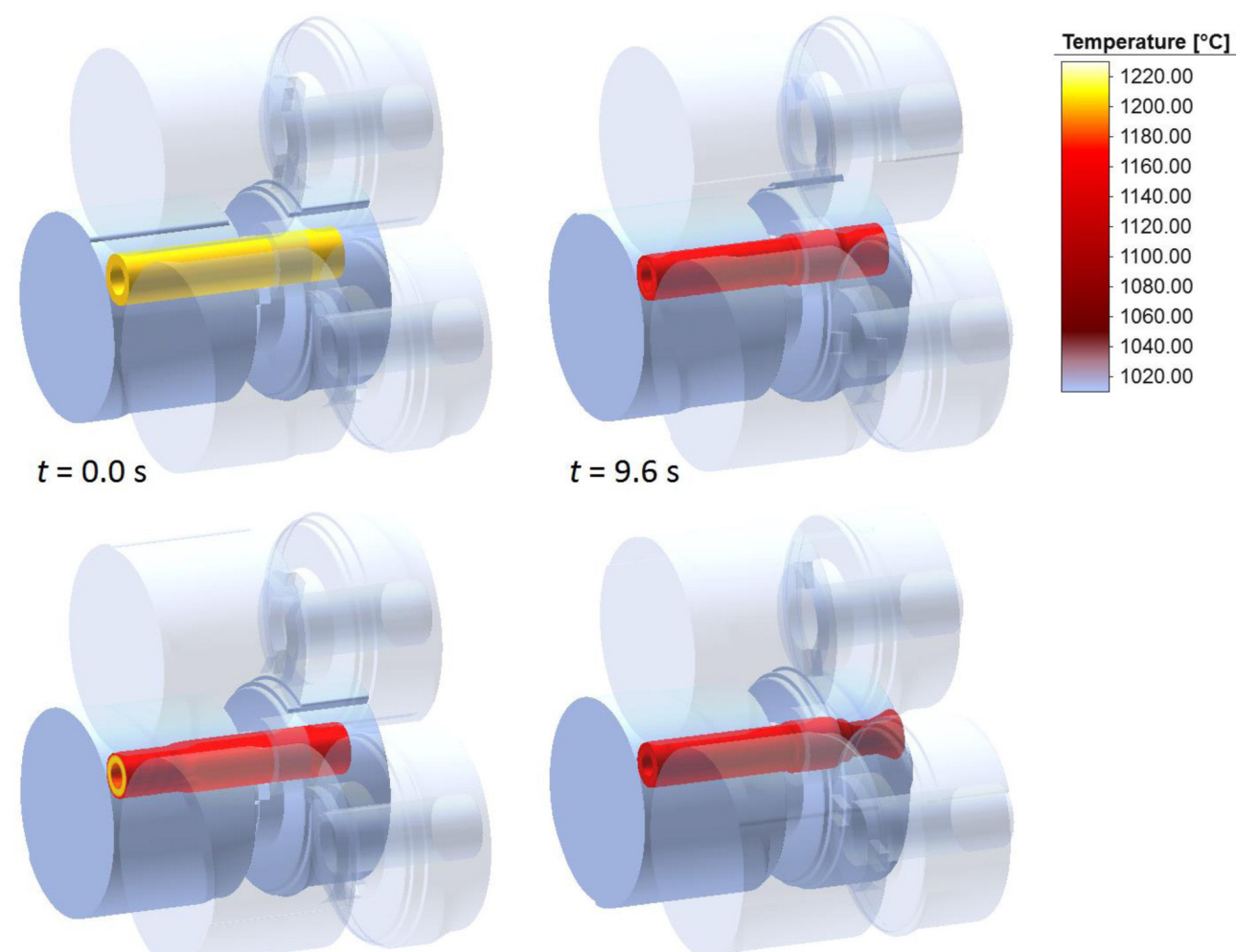

$t=9.6 \mathrm{~s}$

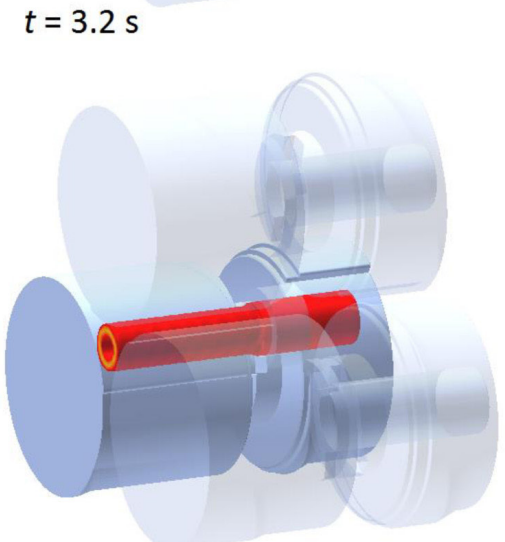

$t=6.4 \mathrm{~s}$

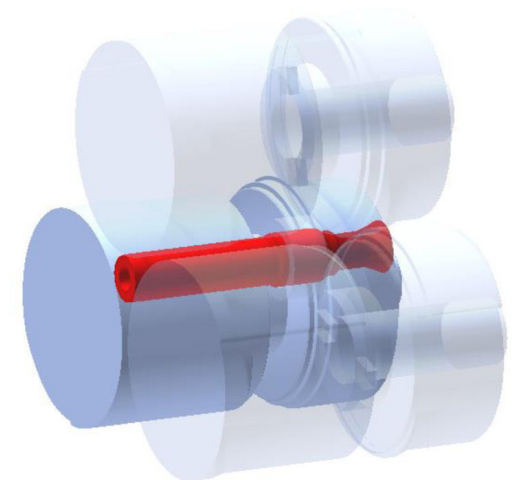

$t=12.8 \mathrm{~s}$

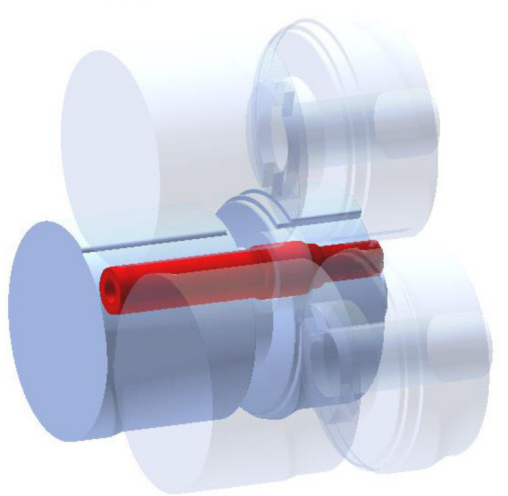

$t=16.0 \mathrm{~s}$

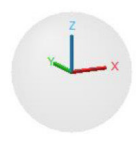

Fig. 5. Progression of the shape of the hollow rail axle formed from a billet with $40 \mathrm{~mm}$-thick wall, the distribution of temperature provided 


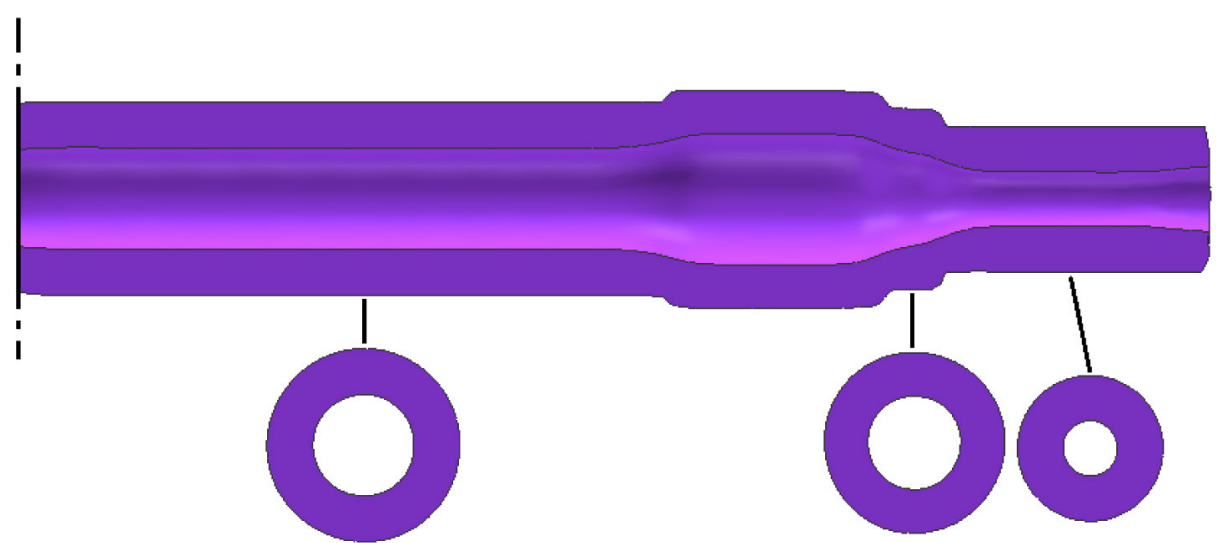

Fig. 6. Cross-sections of the rail axle manufactured by cross-wedge rolling from a billet with $40 \mathrm{~mm}$-thick wall

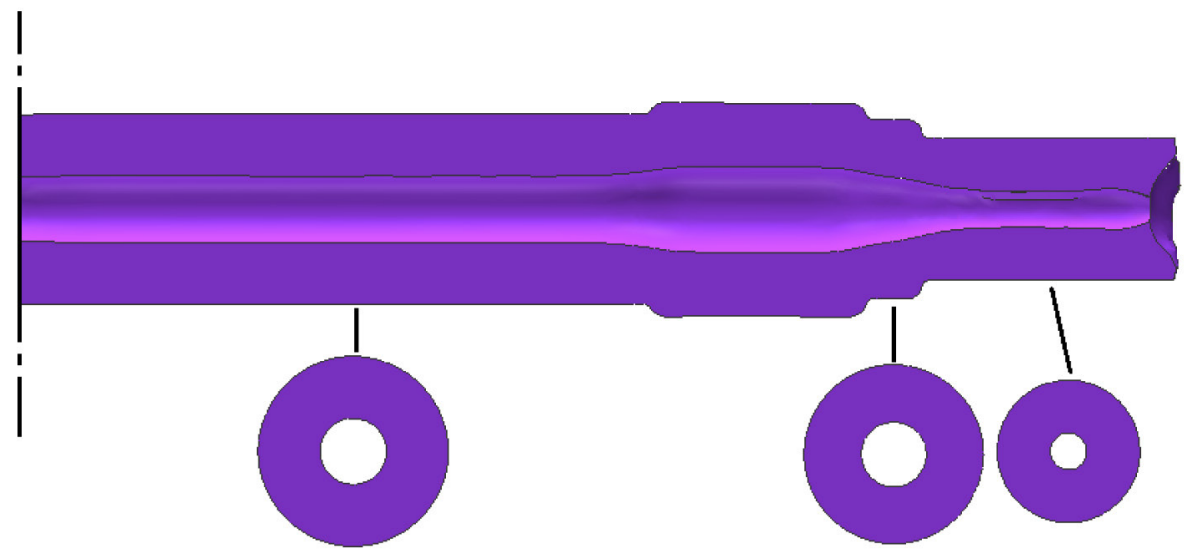

Fig. 7. Cross-sections of the rail axle manufactured by cross-wedge rolling from a billet with $60 \mathrm{~mm}$-thick wall

speaking it can be stated that along with the increase of the billet thickness the material flow in the axial direction also increases.

The thickness of the billet wall does also influence the distribution of the effective strain (fig. 8 and 9). In the case of the thin wall the strain is located nearly evenly throughout its entire thickness, whereas in the case of the thicker wall of the billet more significant strain occurs close to the surface, where the material is acted upon by the friction forces causing the workpiece to rotate. This effect is more visible for the end steps, formed at a more significant reduction.

Despite the relatively long forming time, the temperature of the material in the formed axle did not decrease significantly. According to the data presented in Figure 10 and 11 the temperature on the surface of the workpiece is in the range $1050-1100^{\circ} \mathrm{C}$, whereas inside the walls it is higher by c.a. $50^{\circ} \mathrm{C}$. It can therefore be stated that the parameters of the process were selected properly, since the temperature of the material remained within the range specific to metal forming in hot working conditions.
The developed manufacturing process does not create the environment in which material cracking is likely to occur. This can be assumed upon observing the distribution of the y damage function determined on the basis of the normalized Cockcroft-Latham criterion, shown in Figure 12 and 13. The maximum values of this parameter are lower than 0.8 , while material cracking occurs during cross and wedge rolling, with those values c.a.. three times higher [7]. The beneficial effect does not depend on the wall thickness.

The cross-wedge rolling process is conducted at relatively low values of the power-force parameters. According to Figure 14 the maximum values of the radial loads occur when forming the axle from a billet with $\mathrm{g}_{0}=60 \mathrm{~mm}$. In the case of the central roll the value is equal $960 \mathrm{kN}$, whereas for the side roll $480 \mathrm{kN}$. These values are relatively low, regarding the dimensions of the formed part. For this reason the aggregate used for manufacturing the rail axles with the proposed method will have a light structure.

The energy demand for the aggregate can be estimated on the basis of the torque distribution 


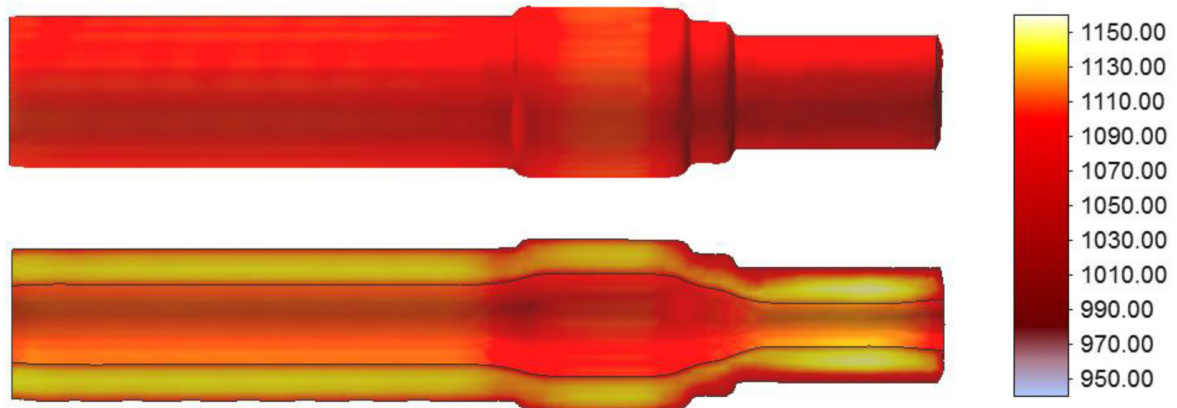

Fig. 8. Distribution of temperature $\left({ }^{\circ} \mathrm{C}\right)$ in a hollow rail axle using the CWR method from a billet with $40 \mathrm{~mm}$-thick wall

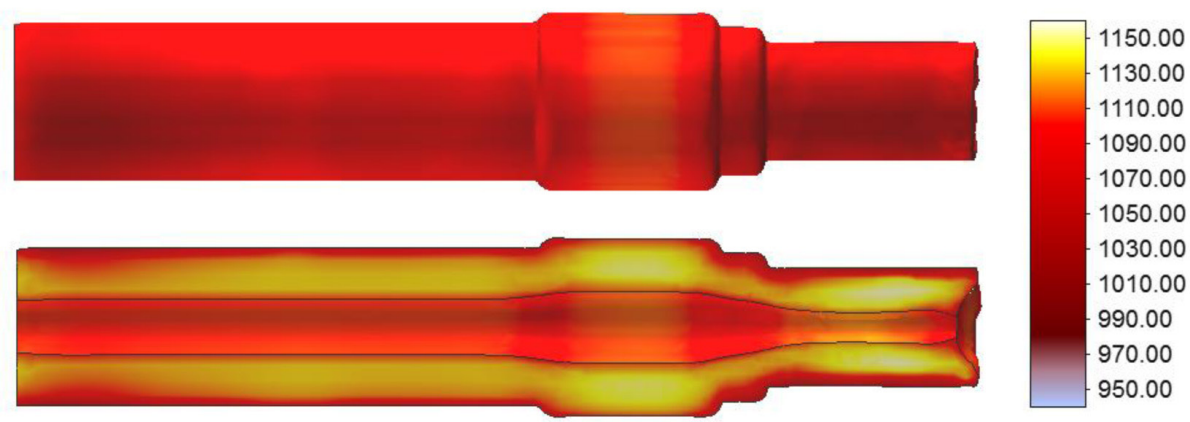

Fig. 9. Distribution of temperature $\left({ }^{\circ} \mathrm{C}\right)$ in a hollow rail axle using the CWR method from a billet with $60 \mathrm{~mm}$-thick wall

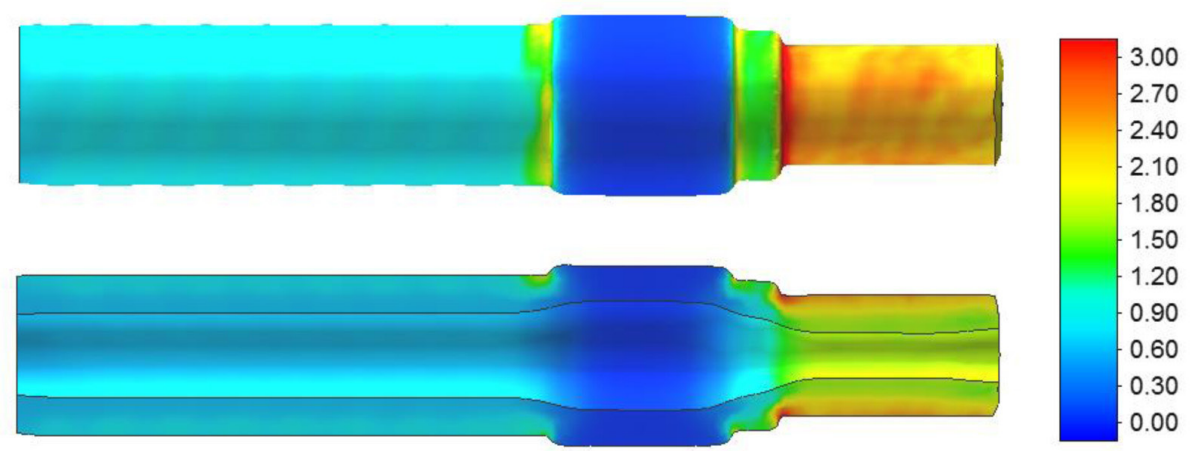

Fig. 10. Distribution of effective strain in a hollow rail axle using the CWR method from a billet with $40 \mathrm{~mm}$-thick wall

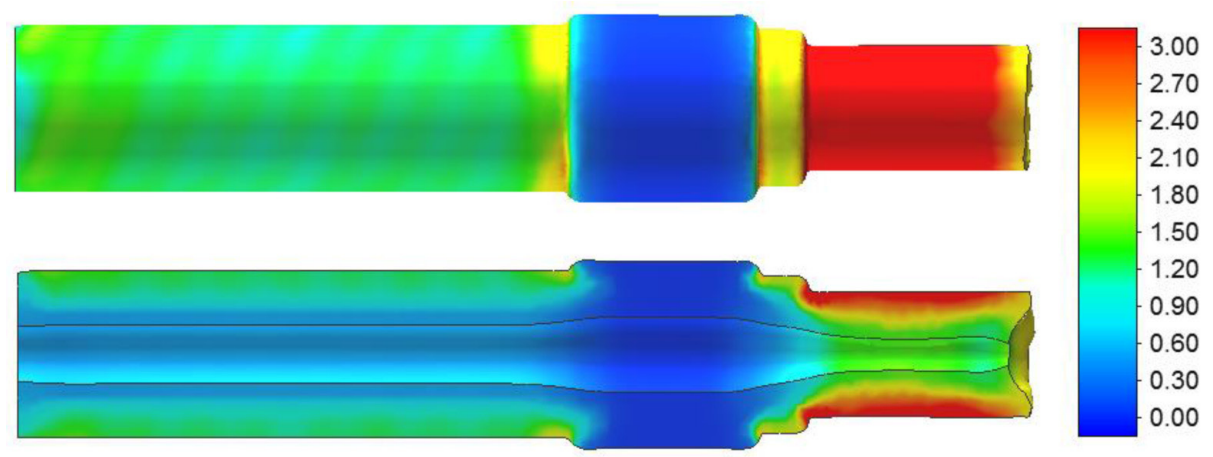

Fig. 11. Distribution of effective strain in a hollow rail axle using the CWR method from a billet with $60 \mathrm{~mm}$-thick wall 


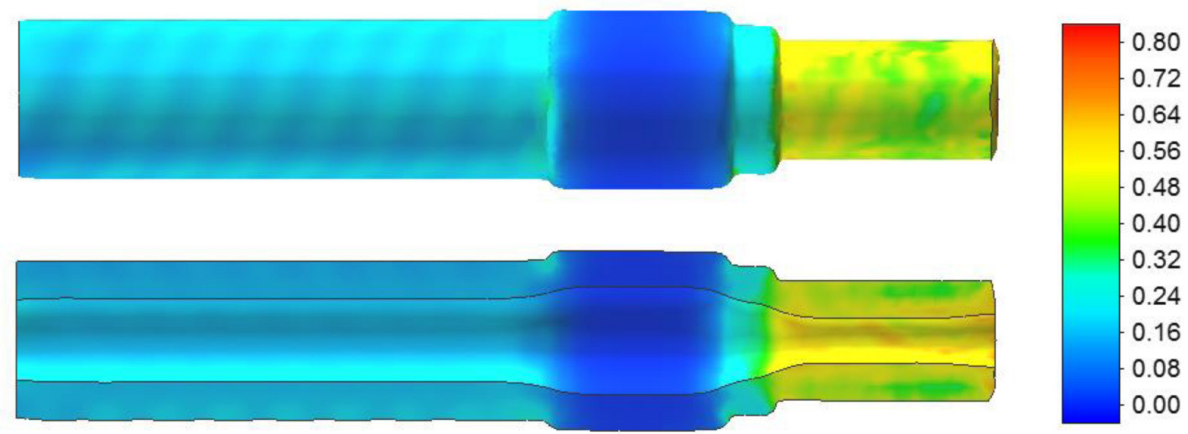

Fig. 12 Distribution of the damage function (determined on the basis of the normalised Cockcroft-Latham criterion) in a hollow rail axle, manufactured in the CWR process from a billet with a $40 \mathrm{~mm}$-thick wall

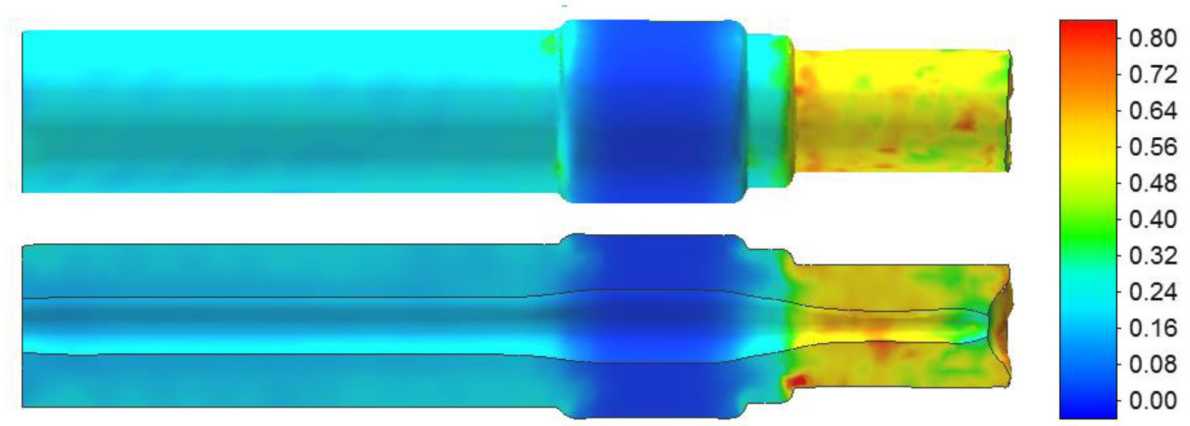

Fig. 13. Distribution of the damage function (determined on the basis of the normalised Cockcroft-Latham criterion) in a hollow rail axle, manufactured in the CWR process from a billet with a $60 \mathrm{~mm}$-thick wall

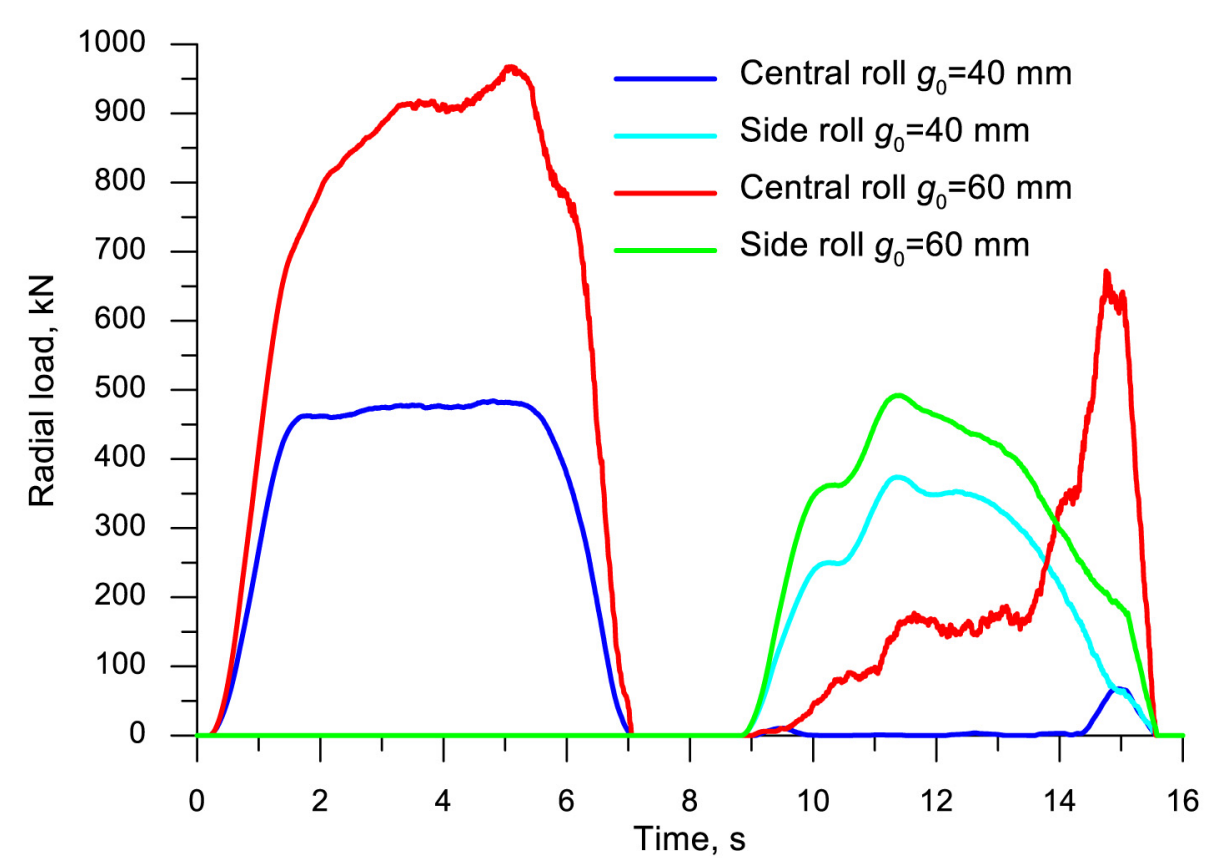

Fig. 14. Distributions of the radial load acting on each roll of the combined tool in the analysed process of manufacturing the hollow rail axle, depending on the thickness of the billet wall $g_{0}$ 


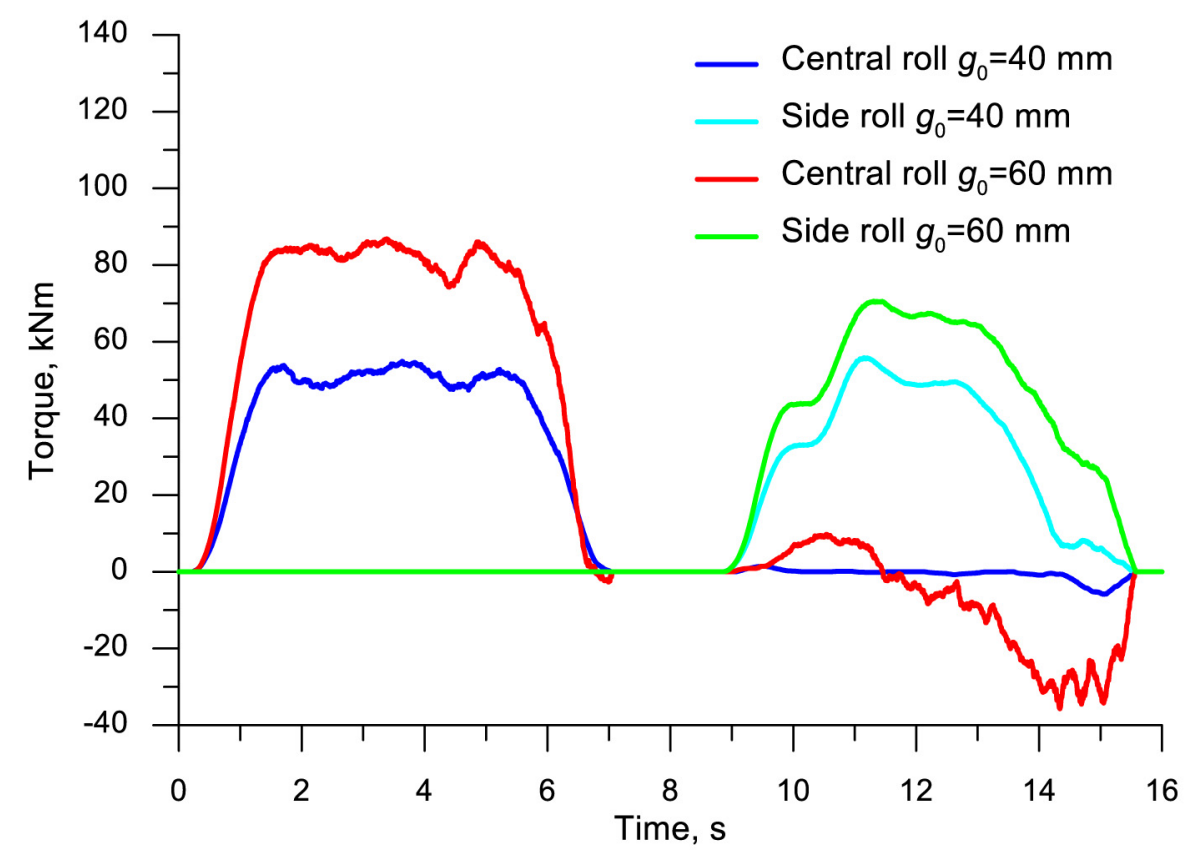

Fig. 15. Distributions of torque on each roll of the combined tool in the in the analysed process of manufacturing the hollow rail axle, depending on the thickness of the billet wall

shown in Figure 15. The maximum values of the torque occur during the second rotation of the rolls, that is when the end steps are formed and are equal c.a. $70 \mathrm{kNm}$ (for each side roll). Considering the fact that two ends of the axle are simultaneously formed it can be safely assumed that the maximum torque for the combined roll is $200 \mathrm{kNm}$. Assuming that the rotational speed of the roll is equal 8 rotations/minute, one can estimate the power of a single drive of the roll to $167 \mathrm{~kW}$. Therefore the estimated power of the aggregate for manufacturing hollow rail axles is equal $500 \mathrm{~kW}$.

\section{CONCLUSIONS}

On the basis of the numerical analysis the following conclusions were drawn:

- The presented method (rolling with three combined rolls) allows one to manufacture hollow rail axles;

- The increase in the thickness of the billet wall influences the wall thickness of the rolled axle, strain distributions as well as the force-energy parameters of the rolling process;

- The risk of the occurrence of inner cracks during the rolling with three combined rolls is very low;

- Despite the relatively long forming time, temperature of the workpiece remains in the range specific for metal forming in hot working conditions;
- The forming forces required for the proposed forming method are relatively insignificant, which means that the aggregate used for manufacturing hollow rail axles will have a light structure; the power of the rolling mill was estimated to be $500 \mathrm{~kW}$.

\section{Acknowledgment}

The research was financed in the framework of the project Lublin University of TechnologyRegional Excellence Initiative, funded by the Polish Ministry of Science and Higher Education (contract no. 030/RID/2018/19).

\section{REFERENCES}

1. Barnicki J. and Pater Z. The aspects of stability in cross-wedge rolling processes of hollowed shafts. J. Mater. Process. Tech., (155-156), 2004, 1867-1873.

2. Bartnicki J. and Pater Z. Numerical simulation of three-rolls cross-wedge rolling of hollowed shaft. J. Mater. Process. Tech., (164-165), 2006, 1154-1159.

3. Kozevnikova G.W., Pipipcuk G.P., Rudovic A.O. and Schukin V.Ja. Progressive method of production of raw railway axles. Technika Zeleznych Dorog, 4(40), 2017, 31-37

4. Pater Z. and Tomczak J. A new cross wedge rolling process for producing rail axles. MATEC Web of Conferences 11006(190), 2018, 1-8. 
5. Pater Z. Cross Wedge Rollin, in: S.T. Button (Ed.), Comprehensive Materials Processing, Elsevier Ltd., 2014, vol. 3, 211-279.

6. Pater Z., Gontarz A. and Weroński W. Cross-wedge rolling by means of one flat wedge and two shaped rolls. J. Mater. Process. Tech., 1-3(177), 2017, 550-554.

7. Pater Z., Tomczak J., Bulzak T., Bartnicki J. and Tofil A. Prediction of Crack Formation for Cross Wedge Rolling of Harrow Tooth Preform. Materials, 2287(12), 2019, 1-16.

8. Peng W., Zheng S., Chiu Y., Shu X. and Zhan L. Multi-wedge cross wedge rolling process of 42CrMo4 Large and Long Hollow Shaft. Rare Metal Mat. Eng, 4(45), 2016, 836-842.

9. Shu X., Wei X., Li C. and Hu Z. The influence rules of stress about technical parameters on synchronous rolling railway axis with multi-wedge cross-wedge rolling. Appl. Mech. Mater., (37-38), 2010, 1482-1488.

10. Urankar S., Lovell M., Morrow C., Li Q. and Kawada K. Development of a critical friction model for cross wedge rolling hollow shafts. J. Mater. Process. Tech., 1-3(177), 2006, 539-544.

11. Urankar S., Lovell M., Morrow C., Li Q. and Kawada K. Establishment of failure conditions for the cross-wedge rolling of hollow shafts. J. Mater. Process. Tech., 1-3(177), 2006, 545-549.

12. Xu C. and Shu X. Influence of process parameters on the forming mechanics parameters of the threeroll skew rolling forming of the railway hollow shaft with 1:5. Metalurgija, 3(57), 2018, 153-156.

13. Zheng S., Shu X., Han S. and Yu P. Mechanism and force-energy parameters of a hollow shaft's multiwedge synchrostep cross-wedge rolling. J. Mech. Sci. Technol., 5(33), 2019, 1-10. 